\title{
Predation, feeding strategy and food daily ration in juvenile European hake
}

\author{
Larissa Modica ${ }^{1, *}$, Anna Bozzano ${ }^{2}$, Francisco Velasco ${ }^{3}$, Giancarlo Albertelli ${ }^{1}$, \\ Ignacio Olaso $^{3}$
}

\author{
${ }^{1}$ DIP.TE.RIS., Dipartimento per lo studio del Territorio e delle sue Risorse, Universita' degli Studi di Genova, \\ Corso Europa 26, 16132 Genova, Italy \\ ${ }^{2}$ Institut de Ciències del Mar (CSIC), Passeig Marítim de la Barceloneta 37-49, 08003 Barcelona, Spain \\ ${ }^{3}$ Instituto Español de Oceanografia, Centro Oceanográfico de Santander, Promontorio de San Martín s/n Santander, \\ 39004 Santander, Spain
}

\begin{abstract}
Predation, feeding strategy (FS) and food daily ration (DR) were analysed in juveniles of the European hake Merluccius merluccius during a $24 \mathrm{~h}$ trawl survey carried out in the northwestern Mediterranean. Predatory activity, expressed as the stomach fullness index (FI) and prey digestion stage, was initiated in the early night and continued throughout the night, reaching maximum activity in the early morning. The feeding activity progressively decreased after this time, reaching a minimum before sunset, when a rest phase was observed. Changes in prey taxa during the $24 \mathrm{~h}$ cycle indicated that prey selection was time-of-day and predator-size dependent. Zooplankton crustaceans were mostly consumed during the night and in the early afternoon. The 2 main categories (euphausiids and mysids) comprising the zooplankton and hyperbenthos trophic resource of the hake, were consumed in a temporally shifted manner, such that the macrozooplankton (euphausiids) was consumed at night and the hyperbenthos (mysids) during the day. FS and length-distribution analysis indicated that early juveniles $(9.3 \pm 1.7 \mathrm{~cm}$ total length, TL) primarily fed on these resources in these periods. In contrast, advanced juveniles $(12.0 \pm 3.4 \mathrm{~cm}$ TL $)$ preyed largely on decapod crustaceans and fishes and fed mostly during the day, exhibiting a more specialised FS. Differences in the DR were estimated using Exponential (Exp) and Squareroot (Sq-r) models, the latter taking into account predator size. The Exp model yielded a mean consumption of $1.5 \%$ body wet weight (BWW) and the Sq-r model yielded mean values ranging between 4.09 and $5.09 \%$ BWW, with a difference between the 2 methods ranging from 63 to $70 \%$ larger for the latter method. Therefore, the application of the Sq-r model gives an alternative insight into the range of consumption in juvenile hakes.
\end{abstract}

KEY WORDS: Feeding strategy $\cdot$ Daily ration $\cdot$ Juvenile Merluccius merluccius $\cdot$ Northwestern Mediterranean

Resale or republication not permitted without written consent of the publisher

\section{INTRODUCTION}

Predator-prey interactions in marine ecosystems are of critical importance in the structuring of marine communities and are important when developing ecosystem models (Bailey et al. 2010). However, both trophic interactions and feeding strategy, i.e. the complex of behaviours (Schoener 1971) of a given organism best suited for gathering food energy in a particular environment, are difficult to understand in the sea because of limitations in studying this environment, and indirect estimates are often necessary for understanding the trophic level that each species occupies.

Direct observation of stomach contents represents a first step towards comprehending the mechanisms 
that regulate trophic relationships, with the objective of understanding the energetic requirements of each species. One way of evaluating the dietary energetic requirements of a species is to estimate the amount of food the species takes in during a periodic cycle, defined as the daily ration of food (DR) in circadian species. In fish, the DR is estimated using data obtained both in laboratory experiments and indirectly from the analysis of food consumption from field data (see Heroux \& Magnan 1996 for a review). The latter approach is common for species that cannot be maintained in experimental conditions, and in the last 2 decades, it has been applied to a multitude of marine organisms, from invertebrates such as krill larvae (Pakhomov et al. 2004) and decapod crustaceans (Maynou \& Cartes 1997, 1998) to top vertebrate predators such as sharks (Bush \& Holland 2002).

In the Mediterranean, studies on the DR of species that occupy key roles in the food webs of the communities living on the shelf-slope break and the upper slope are scarce. The European hake Merluccius merluccius (L. 1758) has great ecological and economic importance in the Mediterranean Sea and the North Atlantic Ocean (Alheit \& Pitcher 1995). Its diet has been widely studied in both Atlantic (González et al. 1985, Guichet 1995, Velasco \& Olaso 1998) and Mediterranean waters (Froglia 1973, Bozzano et al. 1997, Ferraton et al. 2007), and food consumption has been analysed by Velasco \& Olaso (2000), Cartes et al. (2004) and Carpentieri et al. (2008). However, a complete study of the DR in this species during a $24 \mathrm{~h}$ cycle is still lacking, probably because of the difficulties in collecting enough specimens during a daily cycle, where part of the population performs spatial and temporal migrations (Bozzano et al. 2005, Carpentieri et al. 2006, Cartes et al. 2009).

In addition, many studies on food consumption have been carried out using the DR calculation models proposed by Elliott \& Persson (1978) or Eggers (1979), both of which rely on the assumption of an exponential evacuation rate. These methods do not take into account important factors such as predator body length. They also do not analyse in detail some important prey characteristics, such as energy density (the amount of energy stored per unit of weight) or resistance to digestion due to the presence of hard exoskeletons. These aspects have recently been shown to influence evacuation rates and to have an effect on food consumption estimates, as empirically demonstrated by Andersen \& Beyer (2005a) for other gadoids such as cod Gadus morhua, whiting Merlangius merlangus and saithe Pollachius virens.
Therefore, in the present study we (1) estimated the DR of juvenile European hake using two models: a classical exponential model as well as a square root model that takes into account predator length, prey energy density and resistance to digestion, and (2) performed a feeding strategy (FS) analysis. We discuss the diel variation in diet considering the different groups of predators determined in this latter analysis, in order to provide new insight into the role of the European hake as an intermediate in an inverse energy flow between deeper and shallower communities, as recently proposed by Cartes et al. (2009).

\section{MATERIAL AND METHODS}

\section{Collection of samples}

The present study was performed in the northwestern Mediterranean (Catalan Sea) (Fig. 1) in June 2000 on the RV 'García del Cid'. A continuous trawl survey of hauls of approx. $60 \mathrm{~min}$ each was carried out during a $24 \mathrm{~h}$ cycle between 105 and $108 \mathrm{~m}$ depth (Table 1). At this depth the temperature was assumed to be constant at $13^{\circ} \mathrm{C}$ (according to Hopkins 1985 and considering the minimal variations reported by Vargas-Yáñez et al. [2010] during the last 100 yr at the same depth). All of the hake caught were immediately frozen at $-20^{\circ} \mathrm{C}$ to ensure that the digestion of the stomach contents was halted. Once in the laboratory, the specimens were measured (total length, TL)

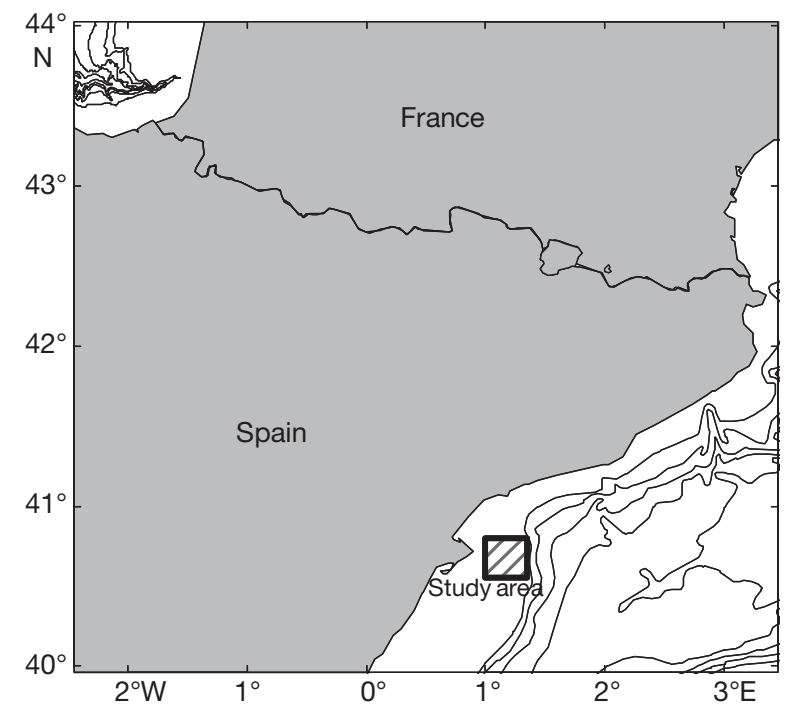

Fig. 1. Study area in the northwestern Mediterranean 
Table 1. Results of a continuous $24 \mathrm{~h}$ trawl survey for European hake Merluccius merluccius in the NW Mediterranean (Catalan Sea) in 2000. Data for sample 9 were replaced with data from a trawl carried out 2 d later in the same place and time. Sunrise and sunset were at 06:20 and 21:29 h, respectively (June 27, Spanish Forecast Institute). TL: total length

\begin{tabular}{|c|c|c|c|c|c|c|c|}
\hline Sample & $\begin{array}{c}\text { Date } \\
(\mathrm{dd} / \mathrm{mm})\end{array}$ & $\begin{array}{c}\text { Mean } \\
\text { depth }(\mathrm{m})\end{array}$ & $\begin{array}{l}\text { Middle time of catch } \\
\text { (hh:mm, GMT) }\end{array}$ & $\begin{array}{l}\text { Sample } \\
\text { size }\end{array}$ & $\begin{array}{c}\text { Empty } \\
\text { stomachs (\%) }\end{array}$ & $\begin{array}{l}\text { Regurgitated } \\
\text { stomachs (\%) }\end{array}$ & $\begin{array}{l}\text { Average fish } \\
\text { TL (cm, } \pm \text { SD) }\end{array}$ \\
\hline 1 & $26 / 06$ & 108 & $18: 03$ & 52 & 23.1 & 28.8 & $9.8 \pm 2.5$ \\
\hline 2 & $26 / 06$ & 106 & $20: 25$ & 55 & 34.5 & 21.8 & $10.5 \pm 3.8$ \\
\hline 3 & $26 / 06$ & 106 & $22: 44$ & 57 & 6.8 & 3.4 & $10.6 \pm 3.5$ \\
\hline 4 & $27 / 06$ & 106 & 03:05 & 82 & 11.0 & 13.4 & $9.9 \pm 2.6$ \\
\hline 5 & $27 / 06$ & 108 & $05: 37$ & 89 & 12.4 & 15.7 & $9.9 \pm 1.9$ \\
\hline 6 & $27 / 06$ & 106 & 08:03 & 101 & 7.9 & 21.8 & $10.1 \pm 2.0$ \\
\hline 7 & $27 / 06$ & 105 & $10: 24$ & 86 & 11.5 & 17.2 & $9.8 \pm 2.1$ \\
\hline 8 & $27 / 06$ & 107 & $14: 40$ & 15 & 21.1 & 0.0 & $10.7 \pm 1.1$ \\
\hline 9 & $29 / 06$ & 108 & $17: 30$ & 143 & 17.4 & 34.7 & $10.4 \pm 2.0$ \\
\hline 10 & $27 / 06$ & 106 & $19: 20$ & 60 & 22.6 & 27.4 & $11.1 \pm 4.4$ \\
\hline
\end{tabular}

to the nearest $0.5 \mathrm{~cm}$ and weighed to the nearest $0.01 \mathrm{~g}$ of wet weight (WW).

\section{Stomach contents analysis}

Stomachs were removed, weighed to the nearest $0.001 \mathrm{~g}(\mathrm{WW})$ and preserved in a $70 \%$ ethanol solution. With respect to their contents, stomachs were classified as full, empty or regurgitated (Table 1). The latter category was assigned when the stomach had no food or very little remains but its walls appeared thin and stretched as in the full stomachs. Prey items were identified and classified to the lowest possible taxonomic level.

A subjective digestion stage, based on appearance and texture, was assigned to each prey item as follows: 1 = fresh; 2 = partially digested; 3 = totally or almost totally digested. Each prey item was weighed, after preservation in $70 \%$ ethanol solution, to the nearest $0.001 \mathrm{~g}(\mathrm{WW})$. To evaluate the weight loss due to preservation in the ethanol solution, a linear regression analysis was performed between the weight of the fresh and preserved stomach contents. Parameters obtained through the regression were used to estimate the original fresh weight of each prey item $\left(\mathrm{r}^{2}=0.91 ; \mathrm{a}=1.2101, \mathrm{~b}=0.0237\right)$. The stomach fullness index (FI) was calculated for each specimen using the following equation:

$$
\mathrm{FI}=\frac{S}{\mathrm{BWW}}
$$

where $S$ is the stomach contents wet weight $(\mathrm{g})$ and BWW is the body wet weight $(\mathrm{g})$ of each individual fish. To reduce the bias due to considering regurgitated stomachs as empty ones, a correction factor for regurgitated stomach contents $\left(R_{\mathrm{c}}\right)$ was applied using Eq. (2), as suggested by Hislop et al. (1991):

$$
R_{\mathrm{c}}=\frac{F+R}{F \times(F+R+E)}
$$

where $F$ is the number of full stomachs we observed, $R$ is the number of regurgitated stomachs and $E$ is the number of empty ones.

\section{Feeding pattern}

The daily cycle in feeding intensity was calculated using all fish specimens in the data set (range 5.5 to $25.5 \mathrm{~cm}$ TL) by employing the mean FI and the digestion stage of each prey item for each haul. The proportion of the prey in each of the 3 digestion stages was tested for significance of difference using a chisquared test. Furthermore, to explore the daily distribution and variation of FI, a non-parametric bootstrap re-sampling was carried out because the application of the correction factor for the regurgitated stomachs did not permit the use of classical parametric statistic tools. The mean FI per haul and the $95 \%$ confidence intervals (CI) from 1000 bootstrap re-samplings (Efron \& Tibshirani 1986) were obtained, and a non-parametric graphical method based on the median was applied to highlight the differences between FI values. A notch was drawn at $\pm 1.58 \mathrm{IQR} / \mathrm{sqrt}(\mathrm{n})$ in each side of the box-plots following Chambers et al. (1983), where IQR corresponds to interquartile range.

To find changes in feeding behaviour related to circadian rhythms, trophic spectrum variations were investigated in terms of prey number and type during the daily period. Because the number of stomachs 
collected in each haul varied widely, normalisation was applied by dividing the number of prey belonging to the main taxa by the number of stomachs analysed in each haul. Additionally, crustacean taxa were split into decapods and zooplankton and hyperbenthos (Euphausiacea and Mysidacea) since the latter group is recognised as one of the most important prey taxa for juvenile hake in the Mediterranean (Orsi-Relini et al. 1997, Ferraton et al. 2007, Carpentieri et al. 2008, Cartes et al. 2009). Finally, the presence and variation in abundance of zooplankton and hyperbenthos crustaceans in the stomach contents were analysed in terms of percent of frequency of occurrence ( $\%$ FO) and digestion stage over time. In addition, differences in percent of occurrence of these 2 categories were analysed over the sampling period in order to determine whether euphausiids (macrozooplankton) and mysids (hyperbenthos) contributed equally to the diet of the juvenile hake.

\section{Feeding strategy}

The FS of juvenile hake was studied by relating the percent of $\mathrm{FO}$ and the percent of abundance of prey type (ith) as suggested by Amundsen et al. (1996). Due to the wide trophic spectrum found in the present study (approx. 30 species identified), only 4 main prey groups were selected: zooplankton crustaceans, decapod crustaceans, benthic fish and benthopelagic fish. The specific abundance of prey according to type $\left(P_{i}\right)$ in terms of taxon was calculated using the following equation:

$$
P_{i}=\left(\sum S_{i} / \sum S_{\text {tot }_{i}}\right) \times 100
$$

where $S_{i}$ is the stomach contents weight comprised of a prey type (i) calculated for each single predator and $S_{\text {tot }_{i}}$ the total stomach contents in only those predators with prey $i$ in their stomachs (Amundsen et al. 1996). Individuals with only small remains of stomach contents or heavily digested food were not included in the analysis (Amundsen et al. 1996). Therefore, to examine the FS, we used 396 stomachs from a total of 740 fish collected. Niche breadth was calculated using index B (Levins 1968). The minimum value of $B, 1$, indicates strongly specialised feeders that prey on a single taxon, while the maximum value of $\mathrm{B}$ (total number of taxa considered) indicates generalist feeders with no preference for any taxa. Kruskal-Wallis and Wilcoxon (with Bonferroni's correction) tests were performed to examine possible differences in the mean TL of fish feeding on different prey groups.

\section{Daily ration}

All calculations of DR were applied to the 0-group individuals whose age was determined by the von Bertalanffy growth function (von Bertalanffy 1960) using parameters $\left(L_{\infty}=108, k=0.21, t_{0}=0.115\right)$ obtained for individuals from the same study area (Aldebert \& Recasens 1996). $\mathrm{L}_{\infty}$ is asymptotic maximum size when $t$ is equal to infinity, $k$ is the growth constant and $t_{0}$ is the hypothetical time when size is equal to zero. The DR was calculated using 2 different mass-dependent models developed by Elliott \& Persson (1978) and Andersen (2001). According to the exponential method (Exp), the food consumption $C_{t}$ during time interval $t$ was calculated using the following equation:

$$
C_{t}=\frac{\left(\mathrm{FI}_{t}-\mathrm{FI}_{t_{0}} \mathrm{e}^{-R_{t}}\right) R_{t}}{1-\mathrm{e}^{-R_{t}}}
$$

where $\mathrm{FI}_{t}$ and $\mathrm{FI}_{t_{0}}$ are the mean FI calculated for 2 consecutive samplings, and $R_{t}$ is the coefficient of gastric evacuation that was calculated using the exponential Elliott (1972) model with the parameters proposed by Durbin et al. (1983) for marine fishes consuming small prey. Mean FI values, used for $C_{t}$ calculations, were obtained from 1000 bootstrap re-sampling replicates, and $95 \%$ associated CI were estimated for each haul. The DR over $24 \mathrm{~h}$ sampling using the Elliot \& Persson model, $C_{(24 E \& P)}$, was calculated using Eq. (4) over the studied time interval $(K=24 \mathrm{~h})$ as follows:

$$
C_{(24 \mathrm{E} \& \mathrm{P})}=\sum_{t=1}^{K} C_{t}
$$

This Exp model assumes that the rate of food consumption within each sampling interval is constant. In the other model applied, the square-root (Sq-r) model of Andersen (2001), estimates of the individual evacuation rate, $\mathrm{d} S \times(\mathrm{d} t)^{-1}$ in $\mathrm{g} \mathrm{h}^{-1}$, expressed as function of the stomach content weight, were obtained as follows:

$$
\frac{\mathrm{d} S}{\mathrm{~d} t}=\rho_{L T E} L^{\lambda} \mathrm{e}^{\delta T} E^{-\mu} S^{0.5} \quad\left(\mathrm{~g} \mathrm{~h}^{-1}\right)
$$

where $L$ is the length of the individual predator $(\mathrm{cm})$, $T$ is the water temperature, $S$ is the stomach content $(\mathrm{g})$ of each predator, $E$ is the prey energy density (cal g ${ }^{-1}$ ) and $\rho_{\text {LTE }}$ the evacuation rate constant depending on $\mathrm{T}, \mathrm{L}$ and $\mathrm{E}$ as defined above.

Where possible, values of the energy density of prey were obtained from the literature, or they were estimated from taxonomically-related species following the criterion of the lower taxonomic level available (see Appendix 1, Table A1). The values we used 


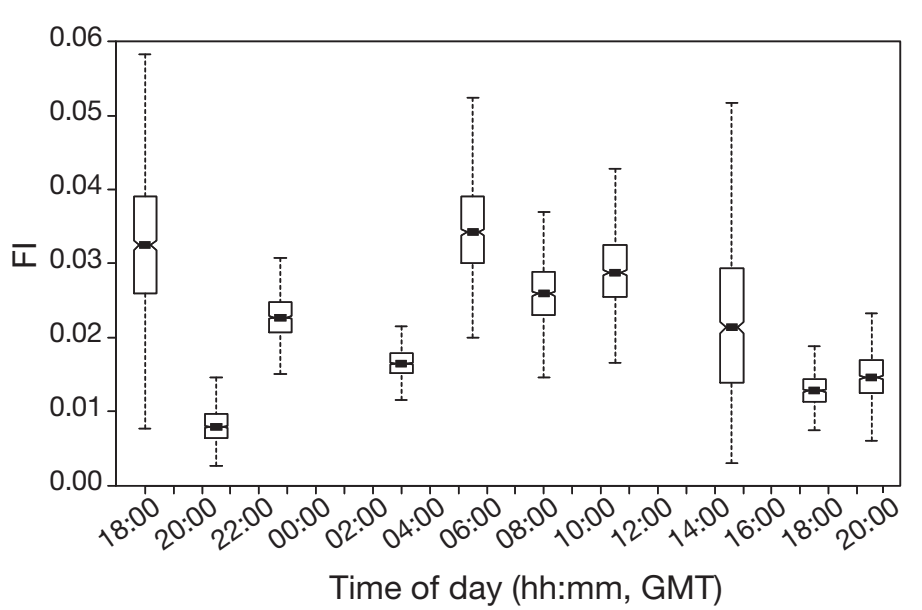

Fig. 2. Merluccius merluccius. Box plots of the stomach fullness index (FI) of juveniles over the study period. Significant differences $(p<0.05)$ are indicated by non-overlap of notches. The box center line represents the median of the fullness indicies distribution of each sampling hour. A notch was drawn at $\pm 1.58 \mathrm{IQR} / \mathrm{sqrt}(\mathrm{n})$ around the median following Chambers et al. (1983), where IQR corresponds to inter quartile range. The limits (hinges) represent an approximation of the 1st and 3rd quartile (further information at http://stat. ethz.ch/R-manual/R-patched/library/graphics/html/boxplot. $\mathrm{html}$ ). The lower whisker represents the distance between the 1st quartile and the smallest observation greater than 1st $\mathrm{Q}-1.5$ (IQR). The upper whisker represents the distance between the 3rd quartile and the greatest observation major than 3rd Q + 1.5 (IQR)

for the predator length exponent $(\lambda=1.44)$, temperature coefficient $(\delta=0.078)$, and coefficient of the energy density of prey $(\mu=0.86)$ were estimated in the Andersen (2001) model for other gadoid species, and have already been used for the European hake in the Cantabrian Sea by Velasco (2007). The values of parameter $\rho_{\text {LTE }}$ used in the present work were calculated by Andersen (2001) for other gadoids. Both Gadus morhua $\left(1.57 \times 10^{-3}\right)$ or Merlangius merlangus and Pollachius virens $\left(1.29 \times 10^{-3}\right)$ values were used to narrow down the range into which hake consumption might fall.

However, Andersen (2001) suggested that this model was more adequate for studying DR in species that feed on fishes and small crustaceans such as krill because the hard exoskeletons contained in a mixed meal slow the evacuation process. Taking into account that Velasco (2007) assumed that digestion time is doubled for hard prey, a correction factor of 0.5 was applied to the calculation of $\rho_{L T E}$ when decapod crustaceans occurred in the stomach contents.

A non-parametric bootstrap re-sampling was applied to the individual evacuation rate with 1000 replicates to estimate the mean daily food consump-

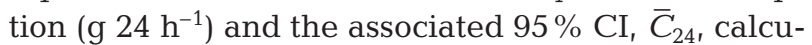
lated using Eq. (7), based on Pennington's (1985) assumption:

$$
\bar{C}_{24}=\alpha \times \operatorname{avg}\left[S(t)^{0.5}\right] \times 24 \mathrm{~h}
$$

where $\alpha=\rho_{L T E} L^{\lambda} \mathrm{e}^{\delta T} E^{-\mu}$ was taken from Andersen (2001).

To compare our results with previous studies, daily consumption estimates were also expressed as a percentage of predator body wet weight ( $\%$ BWW).

\section{RESULTS}

\section{Feeding pattern}

The analysis of diel variation in both FI (Fig. 2) and prey digestion (Fig. 3) suggested an almost constant predatory activity of juvenile hake during the sampled period, with the exception of a rest phase observed before sunset. In fact, a significant percentage of empty stomachs $(34.5 \%)$ was found at $20: 30 \mathrm{~h}$ (Table 1), in correspondence to the minimum value of FI (Fig. 2). Low FI values were found approximately at the same time in the 2 consecutive sampling days (Fig. 2). In addition, undigested and digested prey items were always contemporaneously observed in

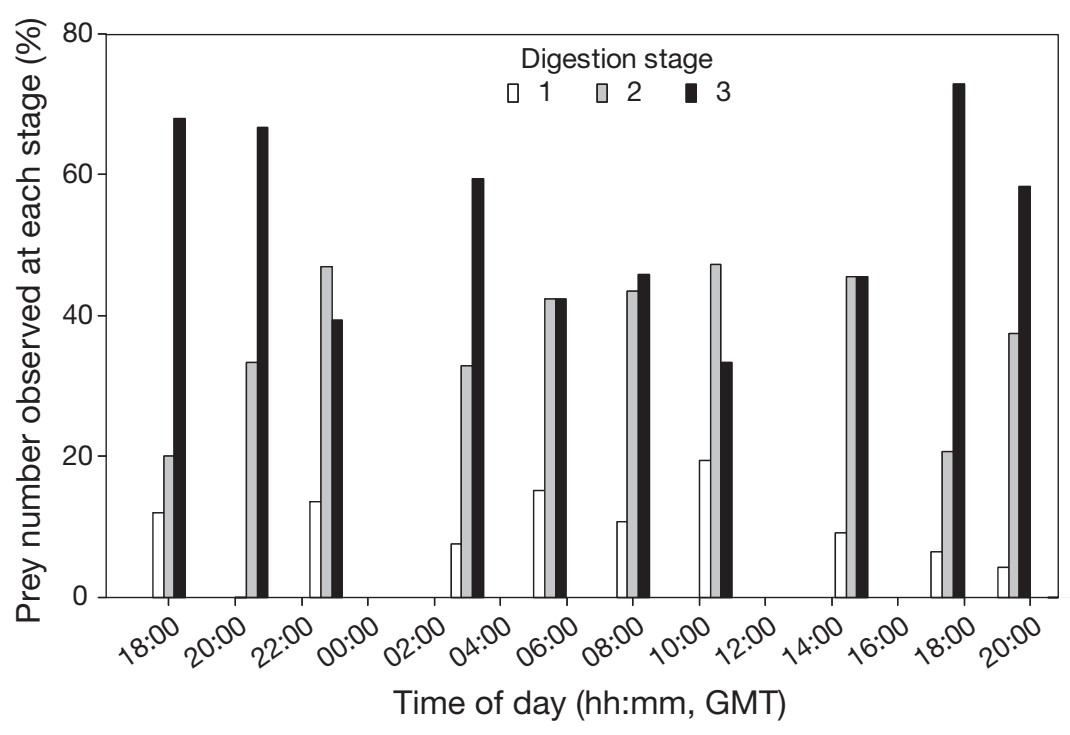

Fig. 3. Merluccius merluccius. Diel changes in digestion stage of stomach contents of juveniles. Stage 1: fresh prey; stage 2: partially digested prey; stage 3: totally or almost totally digested prey 


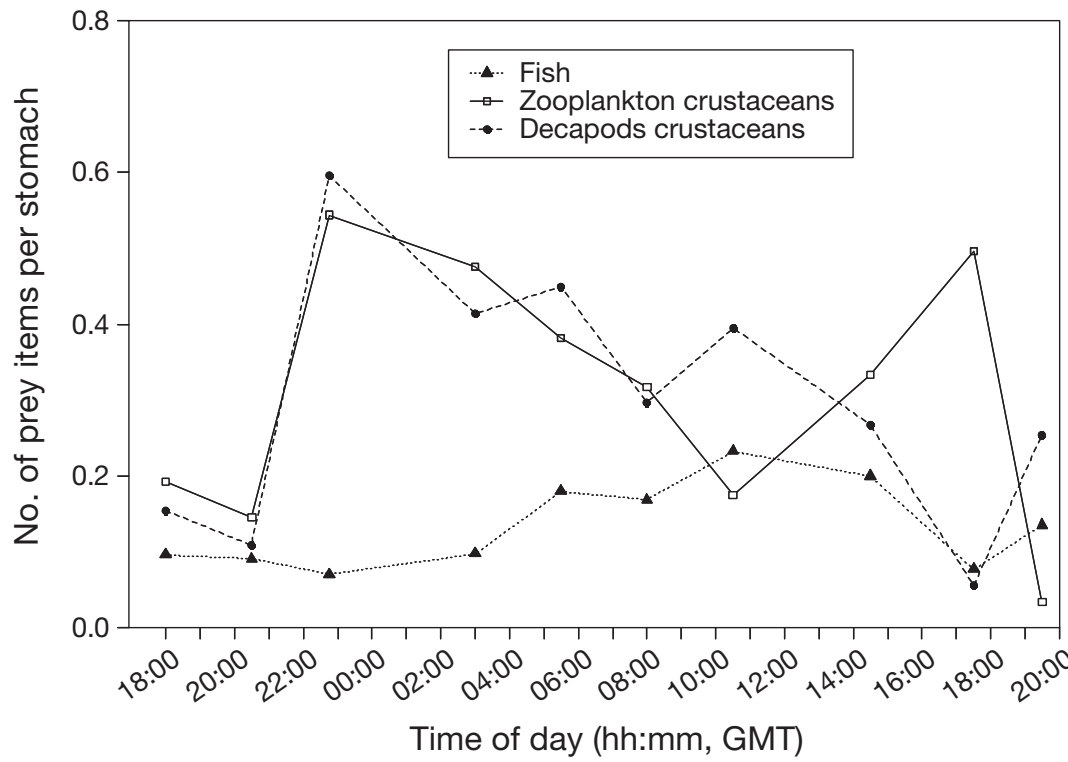

Fig. 4. Merluccius merluccius. Diel variation of the main prey taxa found in the stomach contents of juveniles

the stomach contents, except before sunset when most of the prey were partially or totally digested (Fig. 3). Furthermore, the proportion of prey with different digestion stages varied significantly over the period analysed $\left(\chi^{2}=46.9, \mathrm{p}<0.001\right)$. Therefore, the daily trend in FI values and in prey digestion stages suggests that, in the present study, predatory activity started early in the night and continued all night long, reaching a maximum in the early morning (at 05:37 h, Fig. 2) when the highest values for FI and a high percentage of prey in digestion stage 1 were recorded (Figs. 2 \& 3). A second increase of feeding activity was observed in the morning, when both FI (Fig. 2) and the percentage of undigested prey (Fig. 3) increased at 10:24 h. Levels of FI progressively decreased from this time on, reaching a relative minimum before sunset (17:30 h, Fig. 2).

The prey items ingested by the juvenile hake varied during the sampling period. Zooplankton and hyperbenthos and decapod crustaceans were the most abundant groups in term of number, followed by fishes, while the occurrence of cephalopods (data not shown) was insignificant (Fig. 4). While the decapod crustaceans were preyed upon during almost the entire feeding cycle, and fishes were abundant mainly in the morning, zooplankton and hyperbenthos crustaceans were mostly consumed during the night and in the early afternoon (Fig. 4). In addition, the frequency of occurrence of the former prey category showed the same pattern as number of prey per stomach (Fig. 4), which was also very high during these periods, reaching almost $50 \%$ at night.
Moreover, a remarkable variation in zooplankton categories over time was observed such that, at night, this group was mostly constituted of euphausiids $(69.8 \%)$; in the morning both categories co-occurred, while in the afternoon mysids (95.4\%) were dominant. However, completely undigested zooplankton crustaceans were rarely found in stomach contents. Their occurrence ranged from 0 to $14.8 \%$ of the total zooplankton and hyperbenthos crustaceans analysed, with an average value of $4.5 \%$, probably due to their thin, weak carapaces, as digestion acts faster in this kind of prey than in crustaceans with hard carapaces (Bromley 1994, Andersen 2001).

Taking into account that the samples collected before sunset on 2 consecutive study days showed (1) low values of FI, (2) high levels of prey digestion, (3) similar composition of prey and (4) low occurrence of zooplankton crustaceans, our data indicate that a rest phase in feeding activity occurred in these periods. A schematic summary representing trend in the general feeding activity is provided in Fig. 5.

\section{Feeding strategy}

Analysis of FS, based on the method of Amundsen et al. (1996), showed that the juvenile hake occupies a relatively wide trophic niche (Fig. 6), in agreement with the Levins' index value $(B=2.55)$. Analysis of feeding behaviour showed 2 different predator groups were recognised. The first group, which did not show any specialisation in their FS, was comprised of individuals that fed on zooplankton crustaceans (Fig. 6) and also occasionally preyed on small fishes. The second group fed mainly on decapod crustaceans and benthic and benthopelagic fishes (Fig. 6). Because a high between-phenotype component to the niche width was observed, the second group of predators identified was made up of specialised individuals with little or no overlap in resource use (Fig. 6). In fact, in all of the individuals constituting this group, fishes dominated the stomach contents in terms of weight.

When the body lengths of the 2 groups were analysed, significant differences were observed between them (Kruskal-Wallis test; p < 0.01), with the first group being constituted of early juveniles of $9.3 \pm 1.7 \mathrm{~cm}$ TL and the second group of advanced 


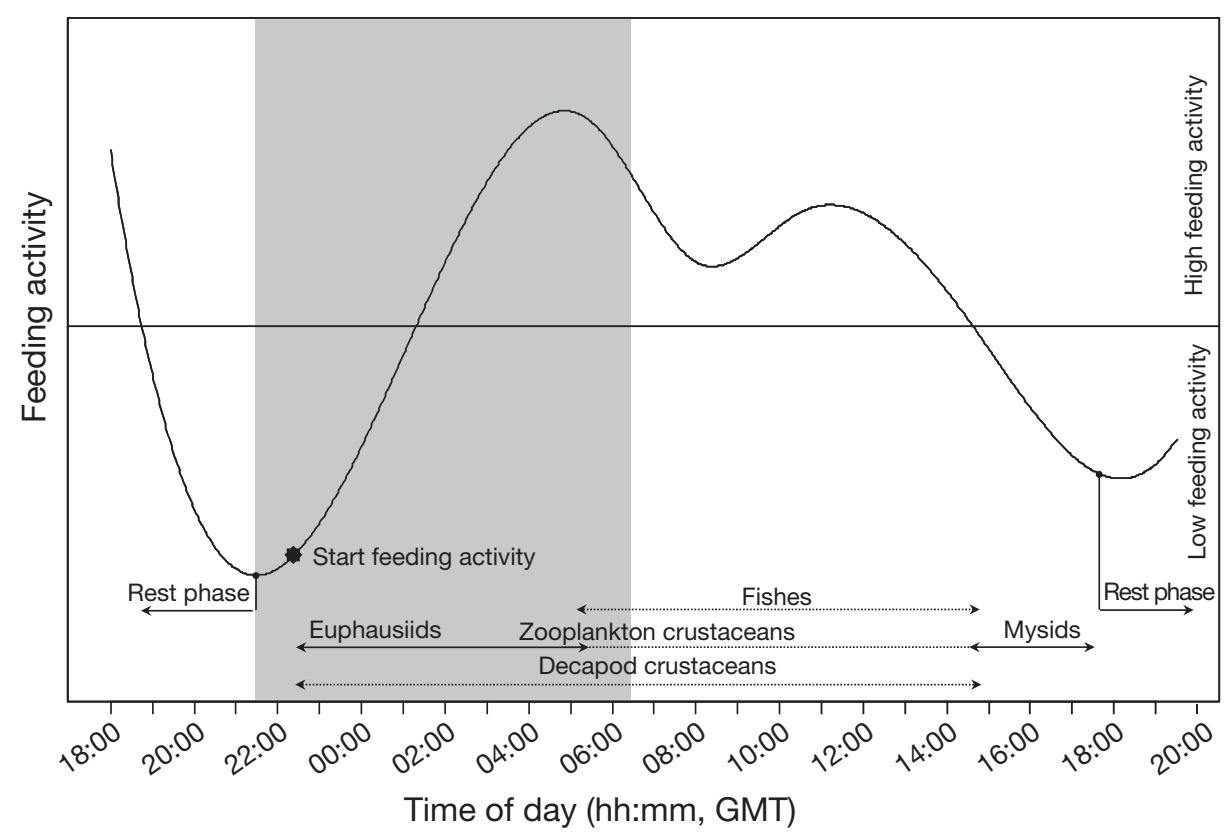

Fig. 5. Merluccius merluccius. Daily trend in the feeding activity of juveniles. The curve indicates the variation of the stomach fullness index (FI) over the study period. The overall median of FI for the $24 \mathrm{~h}$ period is shown by the solid horizontal line. The 3 main taxa found in the stomach contents of the juvenile hake between the 2 feeding rest phases are indicated by dotted lines. The zooplankton line indicates when either euphausiids or mysids were the dominant prey in the stomach contents. The night period is depicted in grey

juveniles of $12.0 \pm 3.4 \mathrm{~cm}$ TL (Fig. 7). Wilcoxon ranksum test pair-wise comparisons enabled us to determine that the mean size of early juveniles feeding on zooplankton crustaceans was significantly different from both that of individuals feeding on decapod crustaceans and benthic fishes $(p<0.01)$ and from that of individuals feeding on benthopelagic fishes $(p<0.05)$. Therefore, early juvenile hake showed a relatively opportunistic FS up to a threshold body size at which their FS changed to a more specialised type.

\section{Daily ration}

The mean stomach contents, expressed as \% BWW with $95 \%$ CI limits, and used to estimate DR using the Exp model, are shown in Table 2. The mean overall stomach content, expressed as \% BWW for the non-regurgitated (full) and empty stomach categories combined, was $2.10 \%$ BWW, while that corrected for regurgitated stomachs was $2.23 \%$ BWW.

Differences in estimates of the DR for juvenile hake were observed between the Elliott \& Persson (1978) Exp and the Andersen (2001) Sq-r models. The Exp model gave a value of $C_{(24 \mathrm{E} \& \mathrm{P})}=1.51 \% \mathrm{BWW}$, using the coefficient of gastric evacuation $R_{t}=0.171$. This coefficient was obtained using the parameters for several marine fishes eating small prey as proposed by Durbin et al. (1983) and applied by these authors to the Elliott (1972) model.

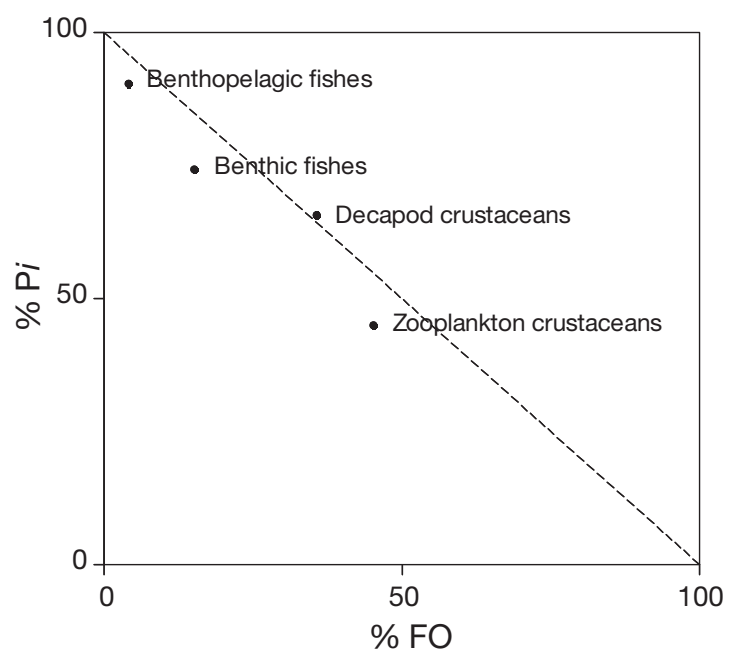

Fig. 6. Merluccius merluccius. Diagram of the feeding strategy of juveniles, where the percent frequency of occurrence (FO) and the percent of specific abundance of prey according to type (Pith) are related. Dots located at the upper left of the diagram indicate a specialised feeding strategy upon these categories of prey. Dots located along or below the diagonal indicate a broad trophic niche 


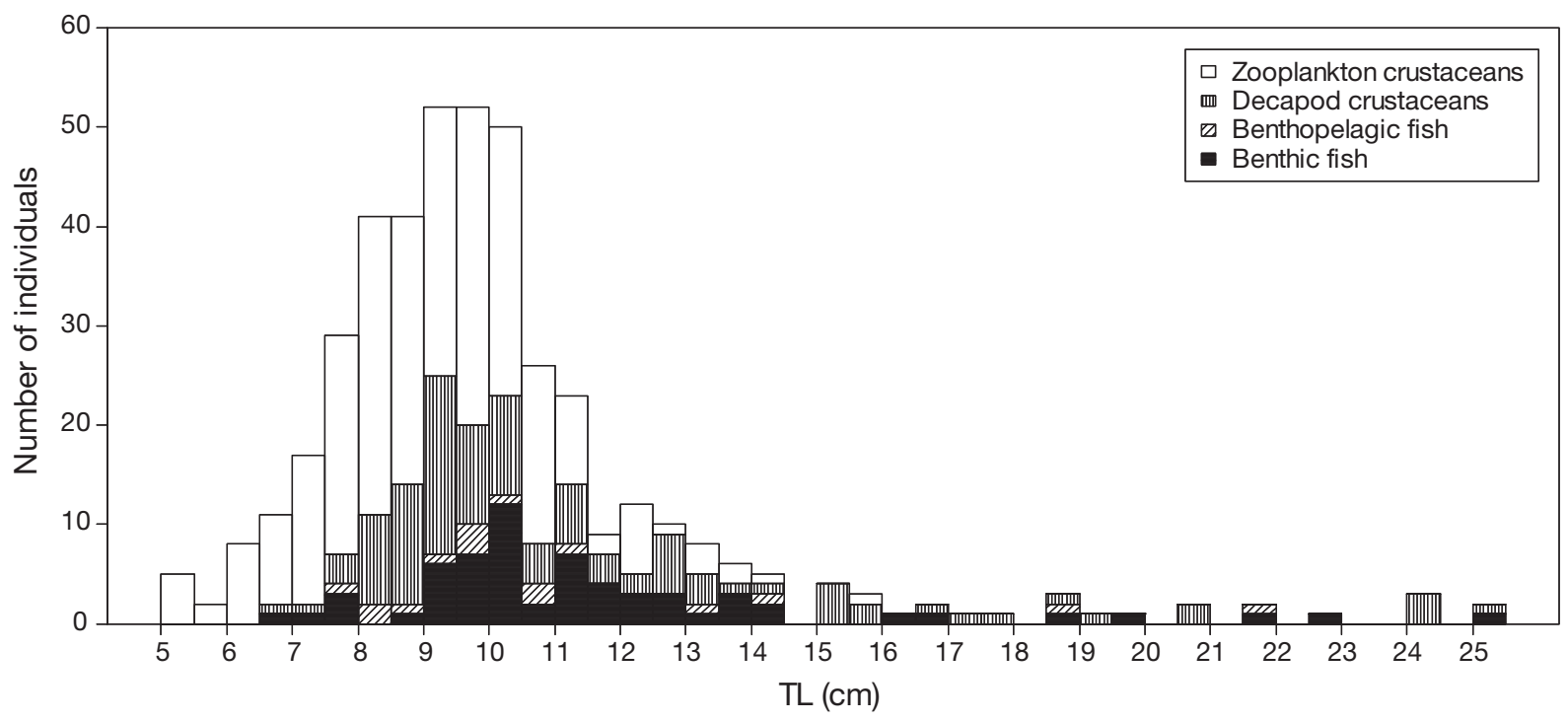

Fig. 7. Merluccius merluccius. Length-frequency distribution of juveniles, feeding on 4 different categories of prey

Instead, the average overall daily consumption values, $\bar{C}_{24}$, obtained with the Sq-r model ranged between 4.08 and $5.09 \%$ BWW (Table 3). These results were obtained applying both the cod and the saithe and whiting parameters (Table 3).

When both models were compared, the differences in mean estimation over the $24 \mathrm{~h}$ period ranged between $63 \%$ (saithe and whiting parameter) and $70 \%$ (cod parameter).

\section{DISCUSSION}

\section{Feeding pattern}

In the present study, juvenile hake fed throughout most of the day except before sunset, when a rest phase was observed. Previous studies on feeding pat-

Table 2. Merluccius merluccius. Estimated values of average stomach content expressed as percentage of body wet weight (\% BWW), lower and upper 95\% confidence interval (CI) after 1000 bootstrap re-samplings for each sampling hour

\begin{tabular}{|lccc|}
\hline $\begin{array}{l}\text { Sampling hour } \\
\text { (hh:mm, GMT) }\end{array}$ & $\begin{array}{c}\text { Stomach content } \\
\text { (\% BWW) }\end{array}$ & $\begin{array}{c}\text { Lower CI } \\
\text { (\% BWW) }\end{array}$ & $\begin{array}{c}\text { Upper CI } \\
\text { (\% BWW })\end{array}$ \\
\hline $18: 03$ & 3.35 & 1.65 & 5.51 \\
$20: 25$ & 0.81 & 0.43 & 1.32 \\
$22: 44$ & 2.27 & 1.72 & 2.84 \\
$03: 05$ & 1.65 & 1.27 & 2.05 \\
$05: 37$ & 3.49 & 2.36 & 5.05 \\
$08: 03$ & 2.60 & 1.84 & 3.57 \\
$10: 24$ & 2.95 & 2.05 & 4.03 \\
$14: 40$ & 2.24 & 0.52 & 4.77 \\
$17: 30$ & 1.30 & 0.88 & 1.77 \\
$19: 20$ & 1.49 & 0.91 & 2.29 \\
\hline
\end{tabular}

terns of hake showed different feeding rhythms; maximum predatory activity was recorded either at night (Carpentieri et al. 2008), during the day (Cartes et al. 2004, Bozzano et al. 2005) or in both periods (Cartes et al. 2009). These discrepancies might be due to the different size ranges of individuals analysed in each study. In addition, seasonality, geographical location and bathymetric distribution may also have an effect on prey availability for hake (e.g. Ferraton et al. 2007, Cartes et al. 2009). In the present study, variations in the use of trophic resources were related to both time of the day and predator size because juvenile hake were collected at the same depth on a daily cycle.

It is of note that euphausiids and mysids, the most abundant resource in the juvenile diet, were consumed in a temporally shifted way during the day, because they do not co-occur and hence the predator in reality has the choice of eating the prey that is there or not eating at all. The nocturnal predation on macrozooplankton (euphausiids), mainly represented by Meganyctiphanes norvegica, a species that dwells mainly on the slope in this period of the

Table. 3. Estimated values of average food consumption expressed in percentage of body wet weight over a $24 \mathrm{~h}$ period (\% BWW $24 \mathrm{~h}^{-1}$ ), lower and upper $95 \%$ confidence interval (CI) after 1000 bootstrap re-samplings for each sampling hour, using the Andersen model with saithe, whiting and cod parameters

\begin{tabular}{|lccc|}
\hline Parameters & Mean & Lower CI & Upper CI \\
\hline Cod & 5.09 & 4.68 & 5.61 \\
Saithe and whiting & 4.08 & 3.66 & 4.54 \\
\hline
\end{tabular}


year, may be explained taking into account the hypothesis of nocturnal oblique migration of euphausiids in the western Mediterranean, proposed by Cartes et al. (2009). These authors pointed out that, during the day, euphausiids were distributed far deeper than juvenile hake; this might explain the major presence of hyperbenthos (mysids) in the hake stomachs during the early afternoon. Even though diet shifts as a function of temporal and spatial prey availability have already been reported for the Cape hake Merluccius capensis in South Africa (Pillar \& Barangé 1995), to our knowledge, this temporal shift in predation on different categories of zooplankton and hyperbenthos of the juvenile European hake has not been described previously. Our results show that during the night, almost half of the analysed individuals profit from euphasiids. Therefore, juvenile European hake in the western Mediterranean could be considered as an intermediate in the energy flow between deeper and shallower water communities as suggested by Cartes et al. (2009).

The feeding cycles of juvenile hake have not been studied enough to empirically demonstrate a periodicity in their feeding behaviour. However, the present results, together with the results of the three $8 \mathrm{~h}$ sampling cycles conducted by Cartes et al. (2004) for the same species in the same area, show that a low prey digestion stage always occurred in the early morning, suggesting a periodicity. Rhythms in feeding behaviour have been found in other Merluccius species (Gordoa et al. 1995) and in other actinopterygians, such as the orange roughy Hoplostetus atlanticus (Bulman \& Koslow 1992). Limited periods of feeding inactivity, which represent an indirect demonstration of a periodicity in feeding behaviour, were also observed in whiting Merlangius merlangus, and seem to be part of the natural feeding pattern in many fishes (Mergardt \& Temming 1997, Rindorf 2003).

\section{Feeding strategy}

A shift in the FS of juvenile hake was observed with body size, as early juveniles exhibited opportunistic foraging behaviour, while advanced juveniles displayed a more specialised FS. Although an ontogenetic shift in hake diet has been reported by several authors (Bozzano et al. 1997, Carpentieri et al. 2005, Ferraton et al. 2007), to our knowledge, the shift in the FS between sub-groups (based on body size) of juvenile hake has not been reported previously. Ontogenetic shifts in diet are often concurrent with a change in habitat (Carpentieri et al. 2005, Fer- raton et al. 2007), while ontogenetic shifts in diet without any change in habitat are less frequent (Horinouchi \& Sano 2000). Internal reorganisation, such as changes in morphology (e.g. mouth gape size) (Feltrin Contente et al. 2009), swimming capacity (Webb 1986) and sensory capabilities (Bozzano \& Catalán 2002) can also cause, as well as result from, diet shifts (Jackson et al. 2004).

It is worth noting that the shift in juvenile hake FS occurred at the same size range at which their visual system undergoes an important transformation (Bozzano \& Catalán 2002). In fact, at this size (12 cm TL), a better photic visual system (driven by cones) and an increase in the ganglion cell density in the retina responsible for a better optical resolution (Mas-Riera 1991, Bozzano \& Catalán 2002) allow advanced juveniles to widen their feeding activity time into the daily period and thus be more selective, even in a more turbid environment (the water-sediment interface), because fast moving and large prey can be detected more efficiently.

These results highlight that juvenile hake belonging to different size sub-groups fed on different prey taxa in a temporally shifted way. Early juveniles fed mainly at night and in the early afternoon on zooplankton, while advanced juveniles fed principally during the day on decapod crustaceans and fishes.

The observed changes in FS with body size also provide information about the fraction of the juvenile population which could take part in the convection of energy from deeper to shallower waters, the early juveniles $(<12 \mathrm{~cm}$ TL) being the main zooplankton consumers and thus the major link in this convection.

\section{Daily ration}

Several authors have stressed the importance of including biological parameters (e.g. body size) in DR models to reduce the bias from considering only the weight of the gut contents (e.g. Andersen 2001, Temming \& Herrmann 2001, Rindorf \& Lewy 2004, Andersen \& Beyer 2005a). Also, Temming \& Andersen (1994) have demonstrated that the exponential model is not suited for the description of gastric evacuation in fish predators if meal size is omitted, especially if extrapolations are made for small amounts of stomach contents as in juveniles. The comparison between the 2 models realised in the present work does rather confirm Temming \& Andersen's (1994) conclusion for the Elliot and Persson Exp model. Nonetheless, this model has been classically accepted and used by several authors (e.g. for European hake; Cartes et al. 
2004, Carpentieri et al. 2008). The consumption estimate obtained using the Exp model falls into the range of food consumption (1.01 to $5.51 \%$ BWW) calculated for the same species by Cartes et al. (2004) from 3 different $8 \mathrm{~h}$ cycles, but it is lower than the value given by Carpentieri et al. (2008), probably because of the different daily sampling periods considered. In fact, Carpentieri et al. (2008) pointed out that no reliable data on stomach fullness were available in their dataset for the night. The lack of samples for the night period and, in particular, for the first part of the night, could have biased their food consumption calculation, resulting in an overestimation, because a low predatory activity phase was observed in this period. In any case, our estimate of $1.51 \% \mathrm{BWW}$ is in accordance with the food DR ( $>1.5 \%$ BWW) reported by Madurell \& Cartes (2005) for other active swimming species, such as sharks, using the quantitative Eggers (1979) model. Our estimate was also higher than for other less active benthic predators, such as Lophius upsicephalus (mean value of $1.07 \pm 0.74 \% \mathrm{BWW}$ ) and Helicolenus dactylopterus (0.07 to $0.46 \%$ BWW, Macpherson 1985).

When using the Andersen Sq-r model, consumption estimates were difficult to compare with previous studies since e.g. Velasco \& Olaso (2000) employed a slightly different Sq-r model and Andersen \& Beyer $(2005 a, b)$ based their calculation on data obtained in the laboratory. However, taking into account what has been demonstrated for the Exp model and the biological parameters (e.g. body size) by Temming \& Andersen (1994), the application of Andersen's Sq-r model provides new insight into the range in which juvenile hakes' consumption might fall. Moreover, this is the first complete $24 \mathrm{~h}$ cycle study of the DR in the juvenile European hake.

Finally, these new insights on trophic ecology in juvenile European hake provide, together with the first estimates of DR, a better understanding of their ecological role and their interactions within the marine ecosystems.

Acknowledgements. The authors thank all of their colleagues who took part in the NERIT cruise for their valuable help during the sampling operations, the crew of the RV 'García del Cid' for their technical support and the Spanish Comisión interministerial de Ciencia Y Tecnología (CICYT), who financed the NERIT project (MAR98-0935). Thanks to J. Cartes, who provided valuable comments on the manuscript. A.B. was funded by the Spanish I3P postdoctoral fellowship (CSIC) and co-financed by the European Social Foundation. L.M. was funded by the Lifelong Learning Programme (Erasmus Placement 2009-2010), funded by the University of Genoa (Italy) and co-financed by the European Community.

\section{LITERATURE CITED}

Aldebert Y, Recasens L (1996) Comparison of methods for stock assessment of European hake Merluccius merluccius in the Gulf of Lions (northwestern Mediterranean). Aquat Living Resour 9:13-22

Alheit J, Pitcher TJ (1995) Hake. Fisheries, ecology and markets, fish and fisheries series 15. Chapman \& Hall, London

Amundsen PA, Gabler HM, Staldvik FJ (1996) A new approach to graphical analysis of feeding strategy from stomach contents data-modification of the Costello (1990) method. J Fish Biol 48:607-614

Andersen NG (2001) A gastric evacuation model for three predatory gadoids and implications of using pooled field data of stomach contents to estimate food rations. J Fish Biol 59:1198-1217

Andersen NG, Beyer JE (2005a) Gastric evacuation of mixed stomach contents in predatory gadoids: an expanded application of the square root model to estimate food rations. J Fish Biol 67:1413-1433

Andersen NG, Beyer JE (2005b) Mechanistic modelling of gastric evacuation in predatory gadoids applying the square root model to describe surface-dependent evacuation. J Fish Biol 67:1392-1412

Arcos JM, Oro D (2002) Significance of fisheries discards for a threatened Mediterranean seabird, the Balearic shearwater Puffinus mauretanicus. Mar Ecol Prog Ser 239: 209-221

Bailey KM, Ciannelli L, Hunsicker M, Rindorf A and others (2010) Comparative analysis of marine ecosystems: workshop on predator-prey interactions. Biol Lett published online 12th May 2010

Barrett RT, Anker-Nilssen T, Gabrielsen GW, Chapdelaine G (2002) Food consumption by seabirds in Norwegian waters. ICES J Mar Sci 59:43-57

Borek KW, Złoch I, Sapota MR, Fijałkowska M, Forycka K (2005) Does food quality affect the conditions of the sand and common gobies from the Gulf of Gdańsk, Poland? Oceanol Hydrobiol Stud 3:39-55

Bozzano A, Catalán IA (2002) Ontogenetic changes in the retinal topography of the European hake, Merluccius merluccius: implications for feeding and depth distribution. Mar Biol 141:549-559

Bozzano A, Recasens L, Sartor P (1997) Diet of the European hake Merluccius merluccius (Pisces: Merluccidae) in the Western Mediterranean (Gulf of Lions). Sci Mar 61:1-8

> Bozzano A, Sardà F, Rìos J (2005) Vertical distribution and feeding patterns of juvenile European hake, Merluccius merluccius in the NW Mediterranean. Fish Res 73:29-36

- Bromley PJ (1994) The role of gastric evacuation experiments in quantifying the feeding rates of predatory fish. Rev Fish Biol Fish 4:36-66

Bulman CM, Koslow JA (1992) Diet and food consumption of a deep-sea fish, orange roughy Hoplostethus atlanticus (Pisces: Trachichthyidae), off southeastern Australia. Mar Ecol Prog Ser 82:115-129

> Bush A, Holland K (2002) Food limitation in a nursery area: estimates of daily ration in juvenile scalloped hammerheads, Sphyrna lewini (Griffith and Smith, 1834) in Kāne'ohe Bay, Ō'ahu, Hawai'i. J Exp Mar Biol Ecol 278: $157-178$

Carpentieri P, Colloca F, Cardinale M, Belluscio A, Ardizzone GD (2005) Feeding habits of European hake (Merluccius merluccius) in the central Mediterranean Sea. 
Fish Bull 103:411-416

Carpentieri P, Colloca F, Belluscio A, Criscoli A, Ardizzone GD (2006) Diel feeding periodicity and daily ration in a demersal fish assemblage. J Mar Biol Assoc UK 86: 853-860

Carpentieri P, Colloca F, Ardizzone GD (2008) Daily ration and feeding activity of juvenile hake in the central Mediterranean Sea. J Mar Biol Assoc UK 88:1493-1501

Cartes JE, Rey J, Lloris D, Gil de Sola L (2004) Influence of environmental variables on the feeding and diet of European hake (Merluccius merluccius) on the Mediterranean Iberian coasts. J Mar Biol Assoc UK 84:831-835

> Cartes JE, Hidalgo M, Papiol V, Massutì E, Moranta J (2009) Changes in the diet and feeding of the hake Merluccius merluccius at the shelf-break of the Balearic Islands: influence of the mesopelagic-boundary community. Deep-Sea Res I 56:344-365

Cauffopé G, Heymans SJJ (2005) Energy contents and conversion factors for sea lion's prey. Fish Cent Res Rep 13: 225-237

Chambers JM, Cleveland WS, Kleiner B, Tukey PA (1983) Graphical methods for data analysis. Chapman \& Hall, New York, NY

Company JB, Sardà F (1998) Metabolic rates and energy content of deep-sea benthic decapod crustaceans in the western Mediterranean Sea. Deep-Sea Res I 45:1861-1880

Durbin EG, Durbin AG, Langton RVV, Bowman RE (1983) Stomach contents of silver hake, Merluccius bilinearis, and Atlantic cod, Gadus morhua, and estimation of their daily rations. Fish Bull US 81:437-454

Eder EB, Lewis MN (2005) Proximate composition and energetic value of demersal and pelagic prey species from the SW Atlantic Ocean. Mar Ecol Prog Ser 291:43-52

Efron B, Tibshirani R (1986) Bootstrap methods for standard errors, confidence intervals and other measures of statistical accuracy. Stat Sci 1:54-77

Eggers DM (1979) Comments on some recent methods for estimating food consumption by fish. J Fish Res Board Can 36:1018-1019

Elliott JM (1972) Rates of evacuation of brown trout, Salmo trutta. Freshw Biol 2:1-18

Elliott JM, Persson L (1978) The estimation of daily rates of food consumption for fish. J Anim Ecol 47:977-991

Feltrin Contente R, Freitas Stefanoni M, Spach HL (2009) Size-related changes in diet of the slipper sole Trinectes paulistanus (Actinopterygii, Achiridae) juveniles in a subtropical Brazilian estuary. PanamJAS 4:63-69

Ferraton F, Harmelin-Vivien M, Mellon-Duval C, Souplet A (2007) Spatio-temporal variation in diet may affect condition and abundance of juvenile European hake in the Gulf of Lions (NW Mediterranean). Mar Ecol Prog Ser 337:197-208

Froglia C (1973) Osservazioni sull'alimentazione del merluzzo (Merluccius merluccius L.) del medio Adriatico. Atti V Cong Naz Soc It Biol Mar Ed. Salentina, Nardò, 1973:327-341

González R, Olaso I, Pereda P (1985) Contribución al conocimiento de la alimentación de la merluza (Merluccius merluccius L.) en la plataforma continental de Galicia y el Cantábrico. Bol Inst Esp Oceanogr 29:211-222

Gordoa A, Macpherson E, Olivar MP (1995). Biology and fisheries of Namibian hakes ( $M$. paradoxus and $M$. capensis). In: Alheit J, Pitcher TJ (eds) Hake: fisheries, ecology and markets. Chapman \& Hall, London, p 49-88 Guichet R (1995) The diet of European hake (Merluccius merluccius) in the northern part of the Bay of Biscay. ICES J Mar Sci 52:21-31

Héroux D, Magnan P (1996) In situ determination of food daily ration in fish: review and field evaluation. Environ Biol Fishes 46:61-74

Hislop JRG, Robb AP, Bell MA, Armstrong DW (1991) The diet and food consumption of whiting (Merlangius merlangus) in the North Sea. ICES J Mar Sci 48:139-156

Hopkins PS (1985) Physics of the sea. In: Margalef R (ed) Western Mediterranean. Pergamon Press, Oxford, p 100-125

> Horinouchi M, Sano M (2000) Food habits of fishes in a Zostera marina bed at Aburatsubo, central Japan. Ichthyol Res 47:163-173

Hunt GLJ, Burgeson B, Sanger GA (1981) Feeding ecology of seabirds of the eastern Bering Sea. In: Hood DW, Calder JA (eds) The Eastern Bering Sea Shelf: oceanography and resources. University of Washington Press, Seattle, WA, p 629-647

Hunt GLJ, Kato H, McKinnel SM (2000) Predation by marine birds and mammals in the subarctic Pacific Ocean. PICES Scientific Report 14, North Pacific Marine Science Organisation, Sidney, BC

Jackson AC, Rundle SD, Attrill MJ, Cotton PA (2004) Ontogenetic changes in metabolism may determine diet shifts for a sit-and-wait predator. J Anim Ecol 73:536-545

Levins R (1968) Evolution in changing environments: some theoretical explorations. Princeton University Press, Princeton, NJ

> Macpherson E (1985) Daily ration and feeding periodicity of some fishes off the coast of Namibia. Mar Ecol Prog Ser 26:253-260

> Madurell T, Cartes JE (2005) Trophodynamics of a deep-sea demersal fish assemblage from the bathyal eastern Ionian Sea (Mediterranean Sea). Deep-Sea Res I 52:2049-2064

> Mas-Riera J (1991) Changes during growth in the retinal structure of three hake species, Merluccius spp. (Teleostei: Gadiformes), in relation to their depth distribution and feeding. J Exp Mar Biol Ecol 152:91-104

- Maynou F, Cartes JE (1997) Field estimation of daily ration in deep-sea shrimp Aristeus antennatus (Crustacea: Decapoda) in the western Mediterranean. Mar Ecol Prog Ser 153:191-196

Maynou F, Cartes JE (1998) Daily ration estimates and comparative study of food consumption in nine species of deep-water decapod crustaceans of the NW Mediterranean. Mar Ecol Prog Ser 171:221-231

> Mergardt N, Temming A (1997) Diel pattern of food intake in whiting (Merlangius merlangus) investigated from the weight of partly digested food particles in the stomach and laboratory determined particle decay functions. ICES J Mar Sci 54:226-242

Orsi-Relini L, Zamboni A, Fiorentino F, Relini G (1997) Vulnerabilità luce-dipendente del nasello (Merluccius merluccius) giovanile. Biol Mar Medit 4:256-262

> Pakhomov EA, Atkinson A, Meyer B, Oettl B, Bathmann U (2004) Daily rations and growth of larval krill Euphausia superba in the eastern Bellingshausen Sea during austral autumn. Deep-Sea Res II 51:2185-2198

Pennington M (1985) Estimating the average food consumption by fish in the field from stomach contents data. Dana 5:81-86

Pillar SC, Barangé M (1995) Diel feeding periodicity, daily ration and vertical migration of juvenile Cape hake off the west coast of South Africa. J Fish Biol 47:753-768 
Rindorf A (2003) Diel feeding pattern of whiting in the North Sea. Mar Ecol Prog Ser 249:265-276

Rindorf A, Lewy P (2004) Bias in estimating food consumption of fish by stomach-content analysis. Can J Fish Aquat Sci 61:2487-2498

Schoener TW (1971) Theory of feeding strategy. Annu Rev Ecol Syst 2:369-404

Steimle FW Jr, Terranova RJ (1985) Energy equivalents of marine organisms from the continental shelf of the temperate Northwest Atlantic. J Northwest Atl Fish Sci 6:117-124

Tarverdiyeva MI (1972) Daily food consumption and feeding pattern of the Georgian cod (Notohteniidae) in the south Georgia area. J Ichthyol 12:684-692

Temming A, Andersen NG (1994) Modelling gastric evacuation without meal size as a variable. A model applicable for the estimation of daily ration of cod (Gadus morhua L.) in the field. ICES J Mar Sci 51:429-438

Temming A, Herrmann JP (2001) Gastric evacuation in horse mackerel. II. The effects of different prey types on the evacuation model. J Fish Biol 58:1246-1256
Vargas-Yáñez M, Moya F, García-Martínez MC, Tel E and others (2010) Climate change in the western Mediterranean Sea 1900-2008. J Mar Syst 82:171-176

Velasco F (2007) Alimentación de la merluza europea ( $M$. merluccius L.) en el mar Cantábrico. PhD thesis, Universidad Complutense de Madrid

- Velasco F, Olaso I (1998) European hake Merluccius merluccius (L. 1758) feeding in the Cantabrian Sea: seasonal, bathymetric and length variations. Fish Res 38:33-44

Velasco F, Olaso I (2000) Hake food consumption in the southern bay of Biscay estimated from a gastric evacuation model. ICES CM 2000/Q:11 (www.ices.dk/products/ CMdocs/2000/Q/Q1100.pdf)

von Bertalanffy L (1960) Principles and theory of growth. In: Nowinskii (ed) Fundamental aspects of normal and malignant growth. Elsevier, Amsterdam, p 137-259

$>$ Webb PW (1986) Effect of body form and response threshold on the vulnerability of 4 species of teleost prey attacked by largemouth bass (Micropterus salmoides). Can J Fish Aquat Sci 43:763-771

Appendix 1. Energy density of prey

Table A1. Merluccius merluccius. Energy density of prey items as gathered from the literature. In order to apply the Andersen (2001) model, data on energy density of prey items found in the stomach contents were gathered from the literature. When data at the species level were unavailable, the criterion of the lower taxonomic level available was applied. If more than one value of energy density existed for a single prey item in the literature, the data from the closest geographical area or from the more recent publication were selected. Values are ranked in taxonomical order and show the energy density of each prey type in accordance with the taxonomical level available. ww: wet weight

\begin{tabular}{|llcl|}
\hline $\begin{array}{l}\text { Prey item found in } \\
\text { stomach contents }\end{array}$ & Taxonomic level available & $\begin{array}{c}\text { Energy density } \\
\text { (J/gWW) }\end{array}$ & References \\
\hline Crustacea & & & \\
Decapoda & & & \\
Alpheus glaber & Plesionika acantonotus & 5071 & Company \& Sardà (1998) \\
Aristeomorpha foliacea & Aristeus antennatus & 5396 & Company \& Sardà (1998) \\
Aristeus antennatus & Aristeus antennatus & 5396 & Company \& Sardà (1998) \\
Chlorotocus crassicornis & Plesionika acantonotus & 5071 & Company \& Sardà (1998) \\
Crangon crangon & Pontophilus norvegicus & 3164 & Company \& Sardà (1998) \\
Parapenaeus longirostris & Parapenaeus longirostris & 4437 & Company \& Sardà (1998) \\
Pontocaris lacazei & Pontophilus norvegicus & 3164 & Company \& Sardà (1998) \\
Pontophilus spinosus & Pontophilus norvegicus & 3164 & Company \& Sardà (1998) \\
Processa canaliculata & Plesionika acantonotus & 5071 & Company \& Sardà (1998) \\
Processa macrophtalma & Plesionika acantonotus & 5071 & Company \& Sardà (1998) \\
Processa spp. & Plesionika acantonotus & 5071 & Company \& Sardà (1998) \\
Upogebia spp. & Crangonidae & 3164 & Company \& Sardà (1998) \\
Unidentified Penaeidae & Parapenaeus longirostris & 4437 & Company \& Sardà (1998) \\
Decapod Crustacea larvae & Crustacea & 4000 & Hunt et al. (1981, 2000) \\
Unidentified Crustacea Decapoda & Crustacea & 4000 & Hunt et al. (1981, 2000) \\
Unidentified Natantia & Crustacea & 4000 & Hunt et al. (1981, 2000) \\
Unidentified Eucaridae & Crustacea & 4000 & Hunt et al. (1981, 2000) \\
Unidentified Crustacea & Crustacea & 4000 & Hunt et al. (1981, 2000) \\
\hline
\end{tabular}


Table A1. (continued)

\begin{tabular}{|c|c|c|c|}
\hline $\begin{array}{l}\text { Prey item found in } \\
\text { stomach contents }\end{array}$ & Taxonomic level available & $\begin{array}{l}\text { Energy density } \\
\text { (J/gWW) }\end{array}$ & References \\
\hline \multicolumn{4}{|l|}{ Euphausiacea } \\
\hline Meganyctiphanes norvegica & Meganyctiphanes norvegica & 3402 & Steimle \& Terranova (1985) \\
\hline Thyssanoessa spp. & Meganyctiphanes norvegica & 3402 & Steimle \& Terranova (1985) \\
\hline Unidentified Euphausiacea & Meganyctiphanes norvegica & 3402 & Steimle \& Terranova (1985) \\
\hline \multicolumn{4}{|l|}{ Amphipoda } \\
\hline Unidentified Amphipoda & Amphipoda & 3274 & Cauffopé \& Heymans (2005) \\
\hline \multicolumn{4}{|l|}{ Mysidacea } \\
\hline Unidentified Mysidacea & Mysis mixta & 2000 & Borek et al. (2005) \\
\hline Siriella norvegica & Mysis mixta & 2000 & Borek et al. (2005) \\
\hline Siriella spp. & Mysis mixta & 2000 & Borek et al. (2005) \\
\hline \multicolumn{4}{|l|}{ Cephalopoda } \\
\hline Alloteuthis spp. & Small cephalopods & 3500 & Hunt et al. $(1981,2000)$ \\
\hline Loligo spp. & Small cephalopods & 3500 & Hunt et al. $(1981,2000)$ \\
\hline Unidentified Ommastrephidae & Small cephalopods & 3500 & Hunt et al. $(1981,2000)$ \\
\hline Unidentified Decapoda & Small cephalopods & 3500 & Hunt et al. $(1981,2000)$ \\
\hline Unidentified Sepiolidae & Small cephalopods & 3500 & Hunt et al. $(1981,2000)$ \\
\hline \multicolumn{4}{|l|}{ Ctenophora } \\
\hline Unidentified Ctenophora & Ctenophora & 170 & Tarverdiyeva (1972) \\
\hline \multicolumn{4}{|l|}{ Echinodermata } \\
\hline Unidentified Echinodermata & Echinodermata & 2171 & Cauffopé \& Heymans (2005) \\
\hline \multicolumn{4}{|l|}{ Osteichthyes } \\
\hline Callionymus maculatus & Callionymidae & 5340 & Arcos \& Oro (2002) \\
\hline Callionymus spp. & Callionymidae & 5340 & Arcos \& Oro (2002) \\
\hline Cataetyx alleni & Genypterus blacodes & 5600 & Eder \& Lewis (2005) \\
\hline Chauliodus sloani & Myctophidae & 6000 & Barret et al. (2002) \\
\hline Chlorophthalmus agassizii & Myctophidae & 6000 & Barret et al. (2002) \\
\hline Citharus linguatula & Pleuronectidae & 5280 & Arcos \& Oro (2002) \\
\hline Gaidropsarus biscayensis & Merluccius merluccius & 4100 & L. Hill pers. comm. \\
\hline Gaidropsarus mediterraneus & Merluccius merluccius & 4100 & L. Hill pers. comm. \\
\hline Lesueurigobius friesii & Gobiidae & 3850 & Borek et al. (2005) \\
\hline Lesueurigobius suerii & Gobiidae & 3850 & Borek et al. (2005) \\
\hline Merluccius merluccius & Merluccius merluccius & 4100 & L. Hill pers. comm. \\
\hline Micromesistius poutassou & Micromesistius poutassou & 4200 & L. Hill pers. comm. \\
\hline Paraliparis leptochirus & Sebastes spp. & 4000 & Barrett et al. (2002) \\
\hline Stomias boa & Myctophidae & 6000 & Barret et al. (2002) \\
\hline Symphurus nigrescens & Pleuronectidae & 5280 & Arcos \& Oro (2002) \\
\hline Trisopterus minutus & Trisopterus esmarkii & 4000 & Barrett et al. (2002) \\
\hline Unidentified Gadidae & $\begin{array}{l}\text { Mean: Micromesistius poutassou } \\
\text { (4200); Merluccius merluccius (4100); } \\
\text { Trisopterus esmarkii (4000) }\end{array}$ & $0)$; & L. Hill pers. comm., Barrett et al. (2002) \\
\hline Unidentified Gobidae & Gobiidae & 3850 & Borek et al. (2005) \\
\hline Unidentified Pleuronectidae & Pleuronectidae & 5280 & Arcos \& Oro (2002) \\
\hline Unidentified Triglidae & Prionotus nudigula & 4630 & Eder \& Lewis (2005) \\
\hline
\end{tabular}

Editorial responsibility: Matthias Seaman, Oldendorf/Luhe, Germany
Submitted: June 10, 2010; Accepted: August 10, 2011 Proofs received from author(s): October 24, 2011 